\title{
Historical and future trends in wetting and drying in 291 catchments across China
}

\author{
Zhongwang Chen ${ }^{1,2}$, Huimin Lei ${ }^{1,2}$, Hanbo Yang ${ }^{1,2}$, Dawen Yang ${ }^{1,2}$, and Yongqiang $\mathrm{Cao}^{3}$ \\ ${ }^{1}$ Department of Hydraulic Engineering, Tsinghua University, Beijing, 100084, China \\ ${ }^{2}$ State Key Laboratory of Hydro-Science and Engineering, Tsinghua University, Beijing, 100084, China \\ ${ }^{3}$ School of Urban Planning and Environmental Science, Liaoning Normal University, Dalian, 116029, China \\ Correspondence to: Hanbo Yang (yanghanbo@tsinghua.edu.cn)
}

Received: 11 November 2016 - Discussion started: 25 November 2016

Revised: 9 March 2017 - Accepted: 27 March 2017 - Published: 26 April 2017

\begin{abstract}
An increasingly uneven distribution of hydrometeorological factors related to climate change has been detected by global climate models (GCMs) in which the pattern of changes in water availability is commonly described by the phrase "dry gets drier, wet gets wetter" (DDWW). However, the DDWW pattern is dominated by oceanic areas; recent studies based on both observed and modelled data have failed to verify the DDWW pattern on land. This study confirms the existence of a new DDWW pattern in China after analysing the observed streamflow data from $291 \mathrm{Chi}-$ nese catchments from 1956 to 2000 , which reveal that the distribution of water resources has become increasingly uneven since the 1950s. This pattern can be more accurately described as "drier regions are more likely to become drier, whereas wetter regions are more likely to become wetter". Based on a framework derived from the Budyko hypothesis, this study estimates runoff trends via observations of precipitation $(P)$ and potential evapotranspiration $\left(E_{\mathrm{p}}\right)$ and predicts the future trends from 2001 to 2050 according to the projections of five GCMs from the Coupled Model Intercomparison Project Phase 5 (CMIP5) under three scenarios: RCP2.6, $\mathrm{RCP} 4.5$, and RCP8.5. The results show that this framework has a good performance for estimating runoff trends; such changes in $P$ play the most significant role. Most areas of China, including more than $60 \%$ of catchments, will experience water resource shortages under the projected climate changes. Despite the differences among the predicted results of the different models, the DDWW pattern does not hold in the projections regardless of the model used. Nevertheless, this conclusion remains tentative owing to the large uncertainties in the GCM outputs.
\end{abstract}

\section{Introduction}

Terrestrial water availability is critical to human lives and economic activities (Milly et al., 2005). In recent decades, changes in water availability have had significant effects on human society (Piao et al., 2010) and the environment (Arnell, 1999) in the context of climate change. Runoff $(Q)$ is a commonly adopted indicator of water availability (Milly et al., 2005). The response of $Q$ to climate change has been widely investigated from basin scale to global scales based on streamflow observations (e.g. Pasquini and Depetris, 2007; Dai et al., 2009; Stahl et al., 2010) or model outputs (e.g. Hamlet et al., 2007; Alkama et al., 2013; Greve et al., 2014).

Under climate change, a trend towards more uneven distribution of the hydrometeorological elements has been detected at the global scale by global climate models (GCMs), both spatially (Held and Soden, 2006; Chou et al., 2009) and temporally (Chou et al., 2013), and by observed data (Allan et al., 2010; Durack et al., 2012; Liu and Allan, 2013). This trend results in probable enhancement of hydrological extremes such as floods and droughts. This response is known as the "rich-get-richer mechanism" (Chou and Neelin, 2004), from which follow-up studies have derived diverse summaries of different elements such as "dry gets drier, wet gets wetter" for precipitation $(P)$ (Allan et al., 2010) and precipitation minus evapotranspiration $(P-E)$ (Held and Soden, 2006), "wet season gets wetter, dry season gets drier" for seasonal precipitation (Chou et al., 2013), and "fresh gets fresher, salty gets saltier" for ocean salinity (Durack et al., 2012; Roderick et al., 2014). Furthermore, these mechanisms have attracted a significant amount of attention in ex- 
ploring whether a similar effect in $Q$ exists on land as the "dry gets drier, wet gets wetter" (DDWW) pattern found in $P-E$, which indicates increasingly uneven distribution of the water resources. The original DDWW pattern predicted a simple active proportional relationship between $P-E$ and $\Delta(P-E)$, where the sign of $P-E$ determines whether a region is dry (negative) or wet (positive). It should be noted that the predicted changes are averages of latitudinal zones rather than values at the local scale (e.g. grid box or catchment). This results in dominance of the oceanic components in the DDWW pattern (Roderick et al., 2014) because $P$ and $E$ are dominated by exchanges over the ocean at most latitudes (Lim and Roderick, 2009). Thus, the DDWW pattern is more appropriately applied to oceans than to land. In fact, because the long-term mean $P-E$ is overwhelmingly positive on land, the method of using the sign of $P-E$ to identify wet and dry regions is no longer feasible because $\Delta(P-E)$ can obviously be negative. Therefore, some scholars attempted to explore a new DDWW pattern to describe changes in the hydrological cycle on land at the local scale. Greve et al. (2014) adopted the aridity index $(\varphi$ $=E_{\mathrm{p}} / P$, where $E_{\mathrm{p}}$ denotes the potential evapotranspiration) to measure the aridity degree and defined $\varphi>2$ as dry regions and $\varphi<2$ as wet regions. Consequently, the pattern became $\varphi>2, \Delta(P-E)<0$, whereas $\varphi<2, \Delta(P-E)>0$. However, the results, based on more than 300 combinations of various global hydrological data sets containing both observed and modelled data, showed that only $10.8 \%$ of land areas robustly followed the adjusted DDWW pattern. Nevertheless, the study of Greve et al. (2014) still has some defects related to two major aspects. The first is the existence of large uncertainties in $E$ in both satellite-based observations and simulations (Kumar et al., 2016), and the second is the artificially assigned threshold between the wet and dry regions, which likely leads to different results when the threshold is changed. Therefore, a study based on observed $Q$ data that are more direct and of relatively low uncertainty should be conducted, and a new method should be adopted to partition dry and wet regions independent of the appointed threshold.

However, it should be noted that the observed changes in $Q$ are responses not only to climate change but also to other factors such as land cover changes and human activities, e.g. withdrawal and drainage (Stahl et al., 2010). To extract the components related only to climate change is an intractable process because no effective method has been presented thus far. Therefore, a roundabout means is to compare credibly estimated changes in $Q$ under climate change with the estimate based on observed data. The Budyko hypothesis (Budyko, 1948) is an effective and simple tool for modelling the mean annual $Q$ within a catchment based only on meteorological information (Koster and Suarez, 1999). The Budyko hypothesis depicts the long-term coupled waterenergy balance for a catchment as
$\bar{E} / \bar{P}=f\left(\bar{E}_{\mathrm{p}} / \bar{P}, c\right)$

where the function $f$ denotes Budyko-like equations, $\overline{E_{\mathrm{p}}}$ is the mean annual potential evapotranspiration, and $c$ is a parameter characterizing a particular catchment. There are various types of Budyko-like equations (e.g. Pike, 1964; Fu, 1981; Choudhury, 1999; Zhang et al., 2001; Yang et al., 2008; Wang and Tang, 2014; Zhou et al., 2015). The Budyko hypothesis has been examined and applied in both observation-based (Zhang et al., 2001; Oudin et al., 2008; Xu et al., 2014) and model-based studies (Zhang et al., 2008; Teng et al., 2012), producing good consistency between observed and modelled data. By analysing hydrometeorological data from 108 non-humid catchments in China, Yang et al. (2007) confirmed that the Budyko hypothesis is capable of predicting $Q$ both at long-term and annual timescales. Xiong and Guo (2012) assessed the Budyko hypothesis in 29 humid watersheds in southern China and found that parametric Budyko formulae can effectively estimate the long-term average $Q$. Therefore, it is reasonable to estimate $Q$ by using the Budyko hypothesis in China. The ability of the Budyko hypothesis to capture the effects of climate change on $Q$, as well as other details, is described in Sect. 2.3.

Based on observed streamflow data from 291 catchments in China, this study first analyses the historical trends in annual $Q$ to explore the possible existence of a DDWW pattern via a new method proposed in Sect. 2.2. Then, by adopting a simple framework derived from the Budyko hypothesis stated in Sect. 2.3, this study estimates the runoff trends caused by climate change in the study catchments to reveal that the historical trends are mainly a response to climate change and to identify the key influencing factor. Moreover, based on the Coupled Model Intercomparison Project Phase 5 (CMIP5) projections of five GCMs, this study predicts changes in $Q$ via the framework to determine whether the DDWW pattern will continue to hold in the future.

\section{Data and methods}

\subsection{Study area and data}

This study collected hydrological and meteorological data from 291 catchments in mainland China with drainage areas ranging from 372 to $142963 \mathrm{~km}^{2}$. These catchments cover all of the first-level basins of mainland China except the Huaihe River basin (Fig. 1). Annual restored discharge data from 1956 to 2000 for each catchment outlet were collected from the Hydrological Bureau of the Ministry of Water Resources of China. Here, the term "restored" means that the effects of human activities on discharge have been mostly removed via the water balance method or other methods. Specifically, the process of restoring the station-observed discharge consists of two major parts: replenishing the con- 


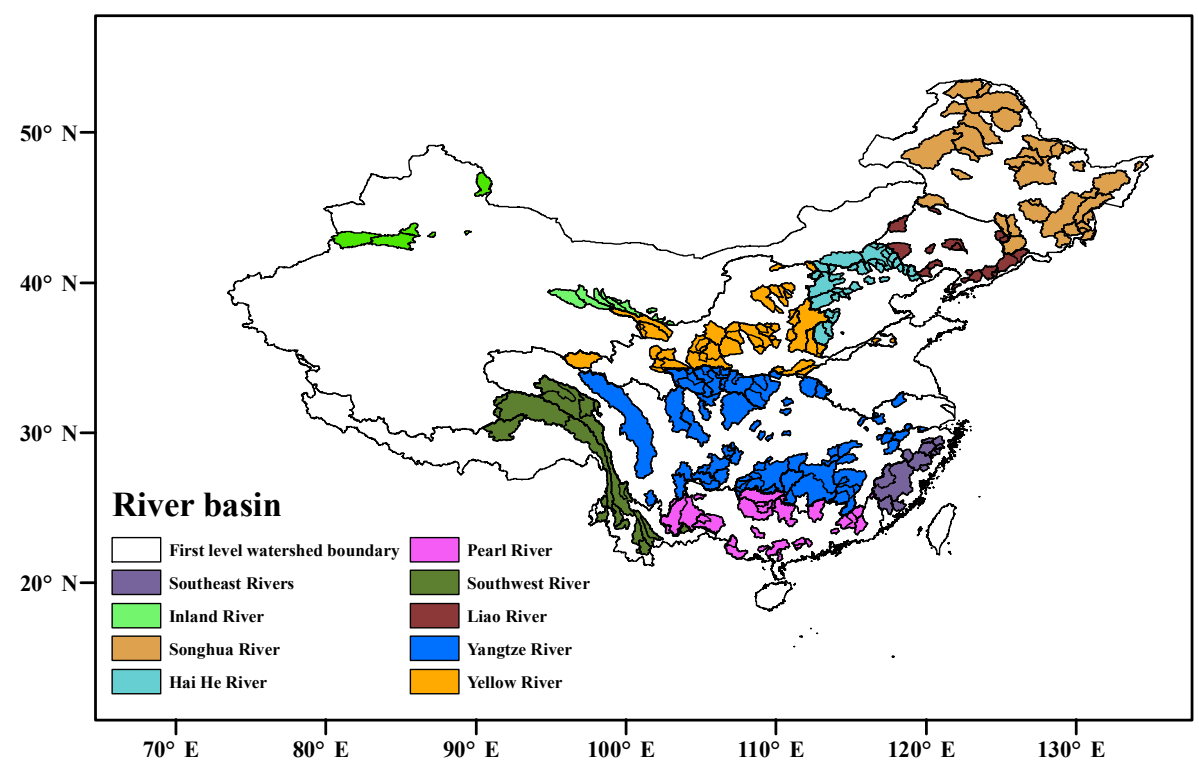

Figure 1. Spatial distribution of the 291 study catchments across mainland China.

sumption and removing the supplement. The water consumption includes the net consumption in agricultural, industrial, and residential sectors as well as water loss in the reservoir owing to evaporation and leakage. The water supplement includes the water diverted from other watersheds and the part of the extracted groundwater supplied back to the river. Changes in the reservoir storage can depend on whether the change is positive or negative. Thus, the restored discharge can be considered as the approximate natural discharge. The records range in length from 21 to 45 years; 261 catchments have record lengths greater than 40 years.

Two meteorological data sets were used in this study. The first is the $10 \mathrm{~km}$ gridded data set interpolated by Yang et al. (2014) based on 736 stations of the China Meteorological Administration, which includes $P$ and potential evapotranspiration $\left(E_{\mathrm{p}}\right)$ observations from 1956 to 2000. Based on this observed data set, the annual areal $P$ and $E_{\mathrm{p}}$ of each catchment were calculated. The other is the daily bias-corrected (Piani et al., 2010; Hagemann et al., 2011) modelled data set from the Inter-Sectoral Impact Model Intercomparison Project (ISI-MIP; http://www.isi-mip.org) covering the period 1951-2050 under scenarios RCP2.6, RCP4.5, and RCP8.5, as released by the CMIP5. The modelled data were initially downscaled to a $0.5^{\circ} \times 0.5^{\circ}$ latitudelongitude grid data set and were then extracted and transformed into the ASCII format by the Institute of Environment and Sustainable Development in Agriculture, Chinese Academy of Agricultural Sciences, China. The output data for each scenario include precipitation; mean, maximum, and minimum air temperature; solar radiation; wind speed; and relative humidity for the five models including GFDLESM2M, HadGEM2-ES, IPSL-CM5A-LR, MIROC-ESM-
CHEM, and NorESM1-M. The daily $E_{\mathrm{p}}$ of each grid was estimated by adopting the Penman equation (Penman, 1948; Appendix A) based on the GCM outputs. The annual series of $P$ and $E_{\mathrm{p}}$ were calculated as the sum of every daily $P$ and $E_{\mathrm{p}}$ over one year. Then, the annual catchment-averaged $P$ and $E_{\mathrm{p}}$ were calculated as the average of gridded $P$ and $E_{\mathrm{p}}$ within one catchment.

\subsection{Runoff trends and DDWW pattern}

In this study, two slightly different methods were used to estimate the runoff trend for the historical (1956-2000) and projected periods (2001-2050), respectively. The runoff trend for the historical period was estimated as the slope of the linear regression of the annual $Q$ series, denoted as $k_{Q}$, and can be calculated by

$k_{Q}=\frac{\sum_{i=1}^{m}\left(t_{i}-\bar{t}\right)\left(Q_{i}-\bar{Q}\right)}{\sum_{i=1}^{m}\left(t_{i}-\bar{t}\right)^{2}}$,

where $m$ is the observed record length of a catchment, $i$ is the $i$ th record, $t_{i}$ is the year of this record, $\bar{t}$ is the average of all recorded years, and $Q_{i}$ and $\bar{Q}$ are the observed annual runoff in $t_{i}$ and the mean annual runoff in the historical period, respectively. The significance of $k_{Q}$ was tested by using a $t$ test. The runoff trend of the projected period, denoted as $\Delta \bar{Q}$, is defined as the change in mean annual runoff between historical and projected periods and can be computed as

$\Delta \bar{Q}=\bar{Q}_{\mathrm{p}}-\bar{Q}$,

where $\bar{Q}_{\mathrm{p}}$ denotes the projected mean annual runoff. 

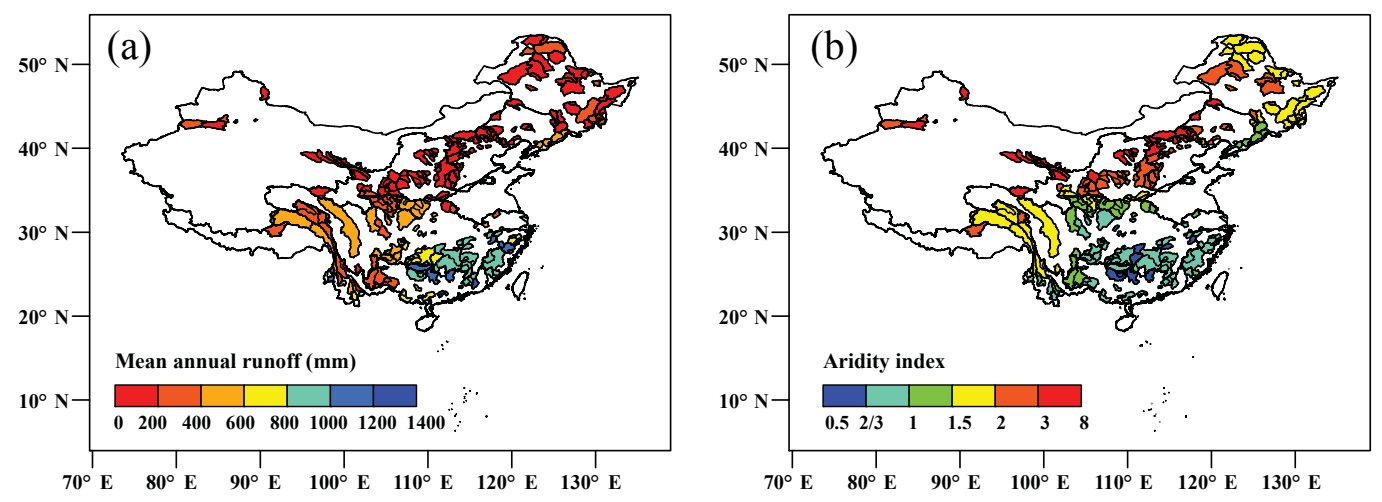

Figure 2. Spatial distribution of (a) mean annual runoff and (b) aridity index $\varphi$ in the 291 study catchments.

In the study of Greve et al. (2014), the DDWW pattern was sensitive to the assigned threshold for defining the dry and wet regions such that different thresholds may have led to different, and possibly conflicting, results. To remove the influence of the threshold, Allan et al. (2010) adopted percentile bins for $P$ to define wet and dry regions, thereby successfully avoiding the pitfalls of selecting a convincing threshold. Therefore, this study does not define absolute wet or dry regions but instead identifies relatively wetter or drier ones. Specifically, two variables, $\bar{Q}$ and $\varphi$, were chosen as indicators of the aridity degree. The term $\varphi$ was introduced to maintain consistency with studies based on the climate model data where $\bar{Q}$ is not available. The spatial distributions of $\bar{Q}$ and $\varphi$ are shown in Fig. 2, with $\bar{Q}$ ranging from 0 to $1400 \mathrm{~mm} \mathrm{a}^{-1}$ and $\varphi$ ranging from 0.5 to 8 . We divided $\bar{Q}$ and $\varphi$ into six intervals, where the intervals with larger $\bar{Q}$ values and smaller $\varphi$ values denoted wetter levels (Table 1). In each interval, the total catchments and catchments becoming wetter were counted, and then the proportion of catchments becoming wetter, denoted as $d$, was calculated. A larger $d$ value implies that more catchments have become wetter in this level. This study compares the $d$ values of different intervals to examine a new DDWW pattern.

\subsection{Framework for estimating runoff trends under climate change}

Among various types of Budyko-like equations, two analytical equations proposed by $\mathrm{Fu}$ (1981) and Yang et al. (2008) should be highlighted. These two equations are able to better capture the role of landscape characteristics because the two studies each introduce a catchment property parameter, $\omega$ and $n$, respectively, as shown by the two examples of $c$ in Eq. (1). Yang et al. (2008) showed a high linear correlation between $\omega$ and $n$. Therefore, this study adopted the equation derived by Yang et al. (2008), which has been rewritten as
Table 1. Details of the interval partitions based on observed mean annual runoff $\bar{Q}$ and aridity index $\varphi$.

\begin{tabular}{lrr}
\hline $\begin{array}{r}\text { Interval } \\
\text { number }\end{array}$ & $\begin{array}{r}\text { Interval } \\
\text { range }\end{array}$ & $\begin{array}{r}\text { Sample } \\
\text { size }\end{array}$ \\
\hline \multicolumn{3}{c}{ Based on $\bar{Q}$} \\
\hline 1 & $0-200$ & 141 \\
2 & $200-400$ & 42 \\
3 & $400-600$ & 31 \\
4 & $600-800$ & 26 \\
5 & $800-1000$ & 32 \\
6 & $1000-1400$ & 19 \\
\hline & Based on $\varphi$ & \\
\hline 1 & $0.5-2 / 3$ & 21 \\
2 & $2 / 3-1$ & 72 \\
3 & $1-1.5$ & 33 \\
4 & $1.5-2$ & 55 \\
5 & $2-3$ & 68 \\
6 & $3-8$ & 42 \\
\hline
\end{tabular}

$\frac{\bar{E}}{\bar{P}}=\left[\left(\frac{\bar{E}_{\mathrm{p}}}{\bar{P}}\right)^{-n}+1\right]^{-1 / n}$.

Focusing on $Q$, this study transformed Eq. (4) into

$\bar{Q}=\bar{P}-\bar{P}\left[\left(\frac{\bar{E}_{\mathrm{p}}}{\bar{P}}\right)^{-n}+1\right]^{-1 / n}$.

The parameter $n$ can be calculated by using the observed $\bar{Q}$, $\bar{P}$, and $\bar{E}_{\mathrm{p}}$ of each catchment from the period 1956-2000. The differential form of Eq. (5) was derived as

$d Q=\frac{\partial Q}{\partial P} d P+\frac{\partial Q}{\partial E_{\mathrm{p}}} d E_{\mathrm{p}}+\frac{\partial Q}{\partial n} d n$,

where $d Q, d P, d E_{\mathrm{p}}$, and $d n$ denote deviations in the observed or modelled $Q, P, E_{\mathrm{p}}$, and $n$ with respect to long-term 
mean values. Equation (6) has widely been used to estimate changes in annual $Q$ (e.g. Yang and Yang, 2011; Roderick and Farquhar, 2011; Roderick et al., 2014).

Because we focused on the effects of climate change, $n$ was assumed to remain unchanged, i.e. $d n=0$ (Yang and Yang, 2011), and Eq. (6) became

$d Q=\frac{\partial Q}{\partial P} d P+\frac{\partial Q}{\partial E_{\mathrm{p}}} d E_{\mathrm{p}}$.

For convenience, we introduced $\varepsilon_{P}$ and $\varepsilon_{0}$ to represent $\frac{\partial Q}{\partial P}$ and $\frac{\partial Q}{\partial E_{\mathrm{p}}}$, which can be estimated on the basis of $n, \bar{P}$, and $\bar{E}_{\mathrm{p}}$ :

$\varepsilon_{P}=\left.\frac{\partial Q}{\partial P}\right|_{\left(\bar{P}, \bar{E}_{\mathrm{p}}\right)}=1-\left[1+\left(\frac{\bar{E}_{\mathrm{p}}}{\bar{P}}\right)^{-n}\right]^{-\frac{n+1}{n}}$

and

$\varepsilon_{0}=\left.\frac{\partial Q}{\partial E_{\mathrm{p}}}\right|_{\left(\bar{P}, \bar{E}_{\mathrm{p}}\right)}=-\left[1+\left(\frac{\bar{E}_{\mathrm{p}}}{\bar{P}}\right)^{n}\right]^{-\frac{n+1}{n}}$.

Roderick et al. (2014) showed that the runoff changes $(=\Delta(P-E)$ in this study) estimated by using Eq. (7) account for about $82 \%$ of the variation in the GCM projections of $\Delta(P-E)$. Therefore, Eq. (7) can predict a reliable result under climate change projected by the GCMs. Based on Eq. (7), a framework can then be constructed to estimate the runoff trends and is interpreted in Appendix B:

$k_{Q_{\mathrm{e}}}=\varepsilon_{P} k_{P}+\varepsilon_{0} k_{E_{\mathrm{p}}}$

$\Delta \bar{Q}_{\mathrm{e}}=\varepsilon_{P} \Delta \bar{P}+\varepsilon_{0} \Delta \bar{E}_{\mathrm{p}}$

where $k_{Q_{\mathrm{e}}}$ and $\Delta \bar{Q}_{\mathrm{e}}$ are estimated runoff trends of the historical and projected periods, respectively; $k_{P}$ and $k_{E_{\mathrm{p}}}$ are the linear regression-calculated trends in annual $P$ and $E_{\mathrm{p}}$, respectively; and $\Delta \bar{P}$ and $\Delta \bar{E}_{\mathrm{p}}$ are changes in $\bar{P}$ and $\bar{E}_{\mathrm{p}}$, respectively.

Equation (8a) and (8b) attribute the runoff trend to two major factors: the precipitation trend and the potential evapotranspiration trend. Equation (8a) estimates $k_{Q_{\mathrm{e}}}$ according to the observed $k_{P}$ and $k_{E_{\mathrm{p}}}$. Equation (8b) estimates $\Delta \bar{Q}_{\mathrm{e}}$ according to the GCM projections, where $\Delta \bar{P}$ and $\Delta \bar{E}_{\mathrm{p}}$ are calculated as the differences in $\bar{P}$ and $\bar{E}_{\mathrm{p}}$ between 1956-2000 and 2001-2050. To measure the uncertainty of the GCMs, the coefficient of variance $\left(C_{\mathrm{v}}\right)$ in each catchment was estimated. $C_{\mathrm{v}}$ is defined as the ratio between the standard deviation and the absolute mean of the five $\Delta \bar{Q}_{\mathrm{e}}$ outputs of the respective GCMs. Specifically, a lower $C_{\mathrm{v}}$ indicates less uncertainty in $\Delta \bar{Q}_{\mathrm{e}}$ because the results of the different GCMs are similar.

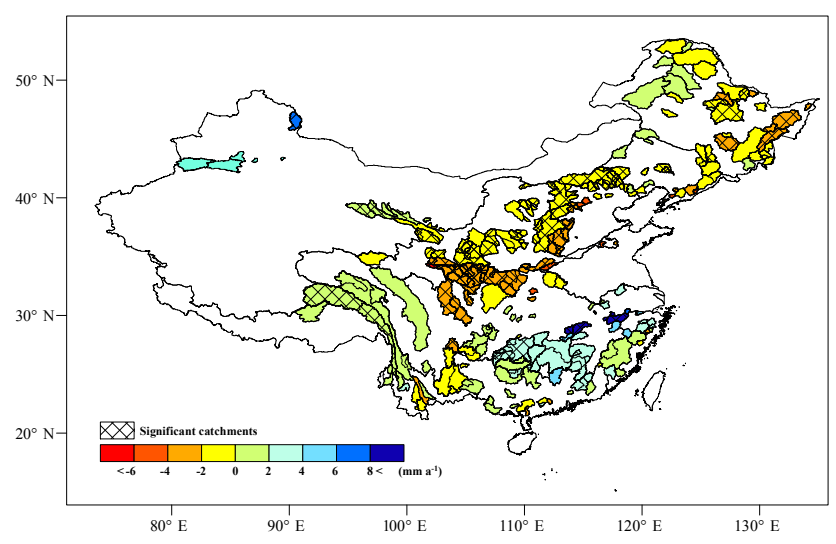

Figure 3. Observed runoff trends $\left(k_{Q}\right)$ in the 291 catchments for the period 1956-2000. The significant catchments are ones experiencing significant changes in runoff at the significance level of 0.05 .

\section{Results}

\subsection{Historical trends in annual runoff}

Figure 3 presents the spatial distribution of the observed $k_{Q}$ in the 291 study catchments. At the significance level of 0.05 , $39.9 \%$ (or 116 of 291) of the study catchments are undergoing significant changes in annual $Q$. These catchments are hereafter referred to as significant catchments. Trends towards wetter conditions (positive trends) were found mainly in the upper and lower reaches of the Yangtze River basin and in the basins of the southwest, southeast, Pearl, and Inland rivers. The annual $Q$ in the lower reaches of the Yangtze River basin and the northern Xinjiang Uyghur Autonomous Region robustly increased by more than $2 \mathrm{~mm} \mathrm{a}^{-1}$, which was greater than the rates of most other catchments. The largest increasing trend of $10.3 \mathrm{~mm} \mathrm{a}^{-1}$ was observed in the Yangtze River basin. However, the catchments in the middle reaches of the Yangtze River basin and in northern and northeastern China experienced the greatest reductions in runoff, generally with significant trends. Several catchments had negative trends of over $4 \mathrm{~mm} \mathrm{a}^{-1}$; the most severe situation was in the Yellow River basin, where the annual $Q$ decreased at a rate of $7.2 \mathrm{~mm} \mathrm{a}^{-1}$.

The relationship between $k_{Q}$ and $\bar{Q}$ is plotted in Fig. 4, which also shows the $d$ for each interval. With an increase in $\bar{Q}, d$ increased from 0.18 to 0.88 , which means that drier regions are more likely to become drier, whereas wetter regions are more likely to become wetter. The slight decrease in $d$ to 0.79 in the last interval can be attributed to the small sample size of this interval; the number of catchments getting drier is actually equal in intervals 5 and 6 (Table 2). Therefore, these results indicate a new DDWW pattern, which emphasizes the fact that the distribution of water resources has become increasingly uneven in China since the 1950s. The process driving the uneven distribution of water resources in this study is powerful because nearly all of the wettest 

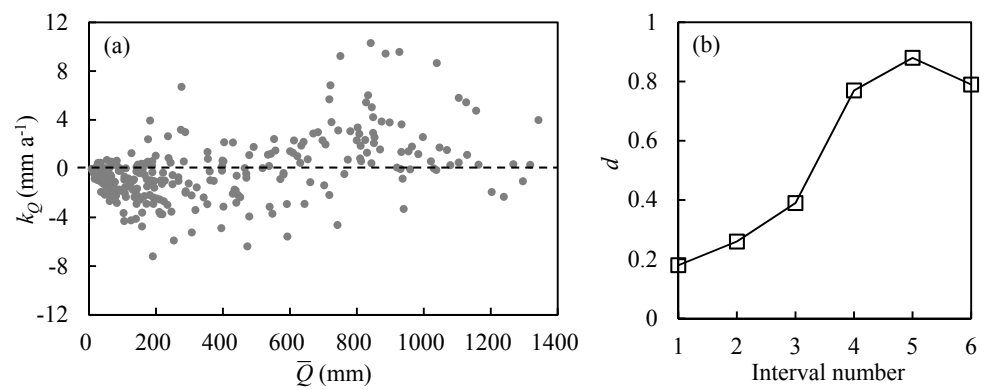

Figure 4. (a) Relationship between observed runoff trends $k_{Q}$ and mean annual runoff $\bar{Q}$ for the study catchments during the period 19562000. (b) Values of $d$ in each interval according to $\bar{Q} \cdot d$ denotes the proportion of catchments with positive trends in each interval. Interval numbers 1 to 6 correspond to six intervals of 0-200, 200-400, 400-600, 600-800, 800-1000, and 1000-1400, respectively.
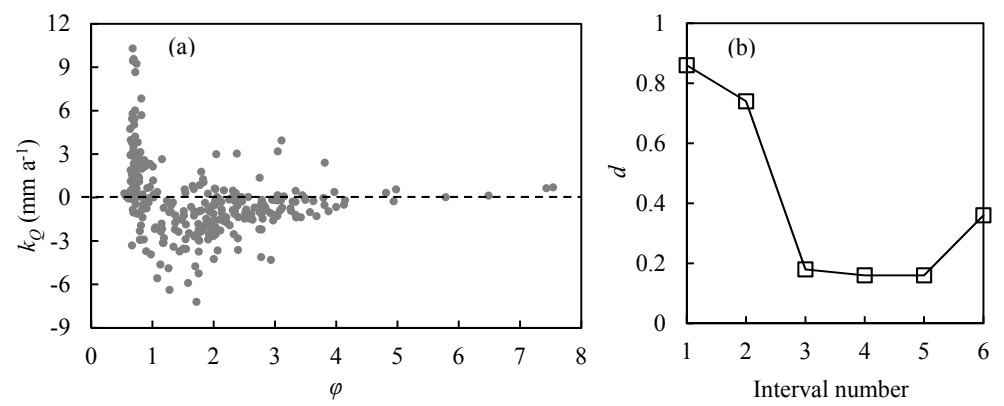

Figure 5. (a) Relationship between observed runoff trends $k_{Q}$ and aridity index $\varphi$ for the study catchments during the period 1956-2000. (b) Values of $d$ in each interval according to $\varphi$. Interval numbers 1 to 6 correspond to six intervals of $0.5-2 / 3,2 / 3-1,1-1.5,1.5-2,2-3$, and 3-8, respectively.
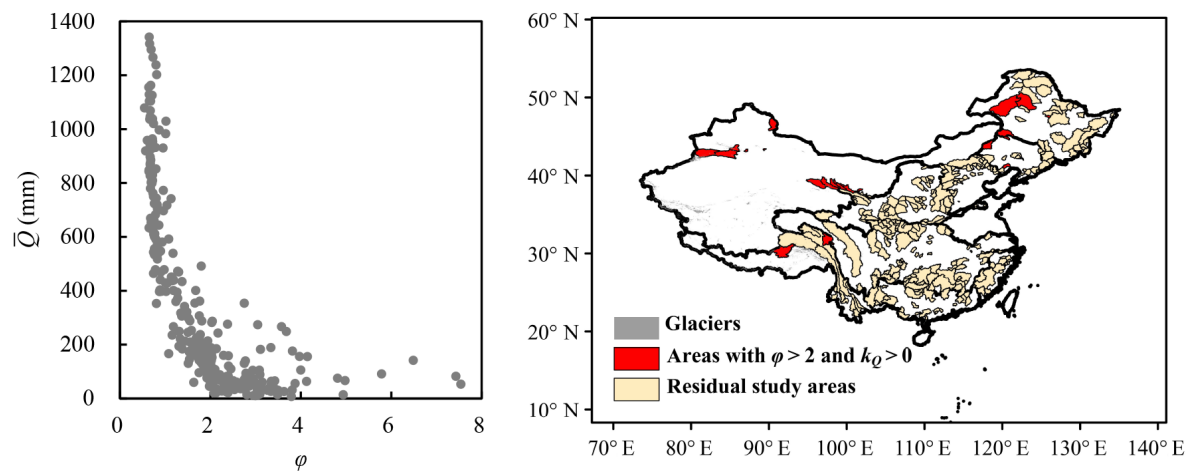

Figure 6. (a) Relationship between mean annual runoff $\bar{Q}$ and aridity index $\varphi$ in the study catchments during the period 1956-2000. (b) Distribution of catchments with $\varphi>2$ and $k_{Q}>0$. Presenting glaciers are based on the second glacier inventory data set of China (Guo et al., 2014).

catchments became wetter, and the driest catchments became drier.

The DDWW pattern was also examined on the basis of $k_{Q}$ and $\varphi$ data. Figure 5 shows that $d$ decreased from 0.86 to 0.16 as $\varphi$ increased, which implies that the DDWW pattern also holds if we adopt $\varphi$ to describe the aridity degree in a manner similar to that reported by Greve et al. (2014). This result can be attributed to the monotonic decrease in
$\bar{Q}$ with $\varphi$ (Fig. 6a). However, $d$ increased sharply to 0.36 in the last interval, in contrast to the DDWW pattern. To understand this divergence, we marked 26 total areas of $\varphi>2$ and $k_{Q}>0$ in Fig. 6b. Surprisingly, most of these areas (19 of 26) were located in areas of glaciers. Therefore, the change in water storage $(\Delta S)$ from the melting of glacial ice and snow also plays a key role in the runoff generation in such regions. However, $\varphi$ does not consider the influence of $\Delta S$, 

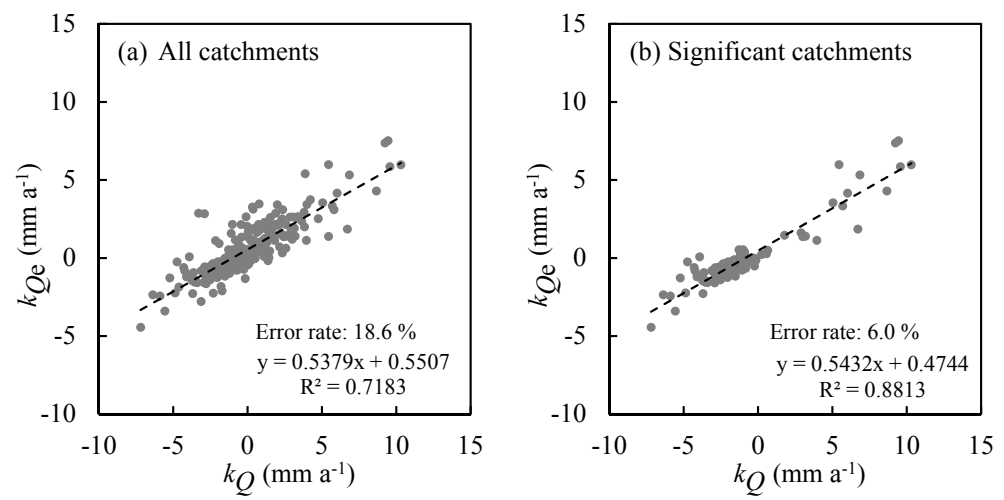

Figure 7. Comparison of estimated runoff trends $k_{Q_{\mathrm{e}}}$ with observed trends $k_{Q}$ for (a) all catchments and (b) significant catchments. Significant catchments are those experiencing significant changes in runoff at the significance level of 0.05 . The error rate is defined as the proportion of catchments in which the signs of the observed and estimated trends differ.

Table 2. Number of catchments with $k_{Q}>0$ and respective $d$ in each interval based on $\bar{Q}$ and $\varphi$ in the analysis of the observed trends. Interval numbers based on $\bar{Q}$ and $\varphi$ are consistent with those in Table 1, as are the interval range and the sample size of each interval. $d$ is the proportion of catchments becoming wetter in each interval.

\begin{tabular}{crc}
\hline $\begin{array}{l}\text { Interval } \\
\text { number }\end{array}$ & $\begin{array}{r}\text { Number of } \\
\text { catchments } \\
\text { with } k_{Q}>0\end{array}$ \\
\hline \multicolumn{3}{c}{ Based on $\bar{Q}$} \\
\hline 1 & 26 & 0.18 \\
2 & 11 & 0.26 \\
3 & 12 & 0.39 \\
4 & 20 & 0.77 \\
5 & 28 & 0.88 \\
6 & 15 & 0.79 \\
\hline & 18 & 0.86 \\
\hline 1 & 53 & 0.74 \\
2 & 6 & 0.18 \\
3 & 9 & 0.16 \\
4 & 11 & 0.16 \\
5 & 15 & 0.36 \\
6 & &
\end{tabular}

thereby leading to an overestimate of the aridity degree in these catchments caused by grouped into the wrong intervals. This reflects the weakness of $\varphi$ in assessing the aridity degree with respect to water resources compared with $\bar{Q}$. Moreover, by acquiring $\Delta S$ and redefining an adjustable aridity index $\left(\varphi^{\prime}\right)$ as $(P-\Delta S) / E_{\mathrm{p}}$, these catchments with high $\varphi$ could also obey the DDWW pattern.

\subsection{Interpreting trends from the climate change perspective}

Based on the comparison of the Budyko-estimated $k_{Q_{\mathrm{e}}}$ with the observed $k_{Q}$, the coefficients of determination $\left(R^{2}\right)$ (Legates and McCabe, 1999) were determined to be 0.70 and 0.86 for all catchments and for significant catchments, respectively (Fig. 7). Therefore, the majority of the runoff trends can be attributed to changes in the atmospheric forcing of water and energy. However, the slope of $k$ was smaller than 1 , at 0.60 and 0.62 for all catchments and significant catchments, respectively, which implies that the Budyko-based framework underestimates the changes in runoff. Nevertheless, despite underestimating the runoff trends, the framework can correctly note the direction of runoff changes in more than $80 \%$ of the study catchments (Fig. 7). This is because the error rates in all and significant catchments, or the proportions of misestimated catchments having different signs of the observed and the estimated trends, are 18.6 and $6.0 \%$, representing 54 of 291 and 7 of 116 , respectively. Furthermore, the DDWW pattern works well based on $k_{Q_{\mathrm{e}}}$ (Fig. 8), which validates the DDWW pattern from the perspective of climate change based on historical meteorological observations. It also indicates the feasibility of using only $P$ and $E_{\mathrm{p}}$ information to examine the pattern and serves as a reference for studies based on climate model outputs.

In catchments where the observed and the estimated signs are consistent, the parts of $k_{Q_{\mathrm{e}}}$ generated from $P$ $\left(k_{Q}^{P},=\varepsilon_{P} k_{P}\right)$ and $E_{\mathrm{p}}\left(k_{Q}^{0},=\varepsilon_{0} k_{E_{\mathrm{p}}}\right)$ were compared to find the factor controlling the runoff changes owing to climate change. As shown in Fig. 9, $k_{P}$ makes an overwhelming contribution in $88.6 \%$ (or 210 of 237) of these catchments because the ratios of absolute $k_{Q}^{0}$ to absolute $k_{Q}^{P}$ are smaller than 1 . Moreover, when linking $k_{P}$ with $\bar{Q}$ (Fig. 10), we observed a pattern similar to that of DDWW, i.e. more precipitation in wetter areas and less in drier areas. This pattern is the result of the dominant position of $k_{P}$ and the positive effect 

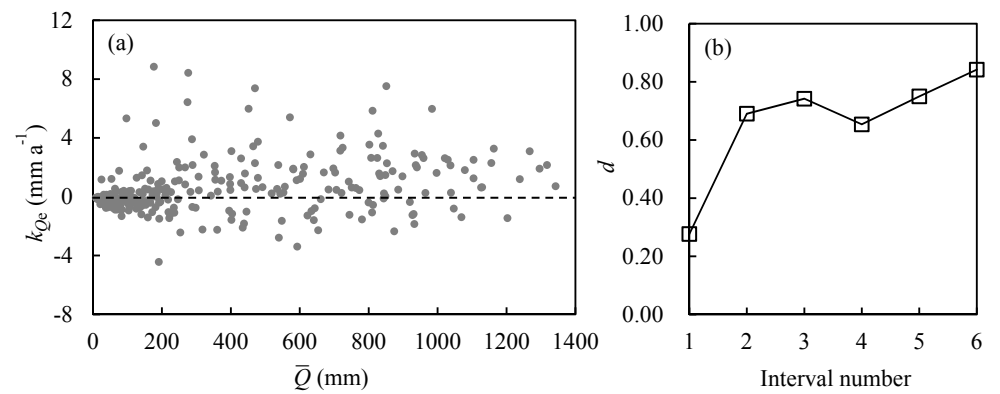

Figure 8. (a) Relationship between estimated runoff trends $k_{Q_{\mathrm{e}}}$ and mean annual runoff $\bar{Q}$ for the study catchments during the period 19562000. (b) Values of $d$ in each interval according to $\bar{Q}$. Interval numbers 1 to 6 correspond to six intervals of 0-200, 200-400, 400-600, 600-800, 800-1000, and 1000-1400, respectively.
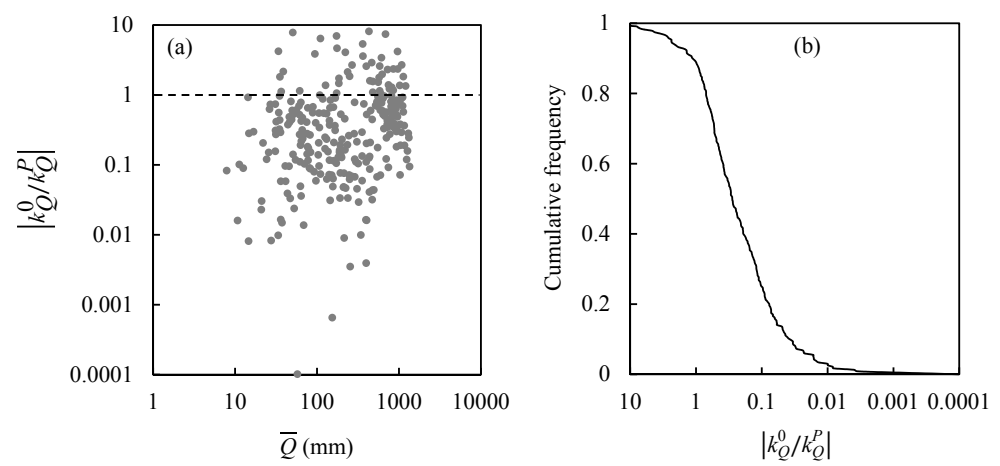

Figure 9. Analysis of the controlling factor in the DDWW pattern according to the Budyko hypothesis. (a) Relationship between the ratio of absolute $k_{Q}^{0}\left(=\varepsilon_{0} k_{E_{\mathrm{p}}}\right.$, the part of the estimated runoff trends $k_{Q_{\mathrm{e}}}$ generated from potential evapotranspiration changes) to absolute $k_{Q}^{\mathrm{P}}$ $\left(=\varepsilon_{\mathrm{P}} k_{\mathrm{P}}\right.$, the part of $k_{Q_{\mathrm{e}}}$ generated from precipitation changes) and the mean annual runoff $\bar{Q}$. (b) Cumulative frequency curve of $\left|k_{Q}^{0} / k_{Q}^{\mathrm{P}}\right|$.
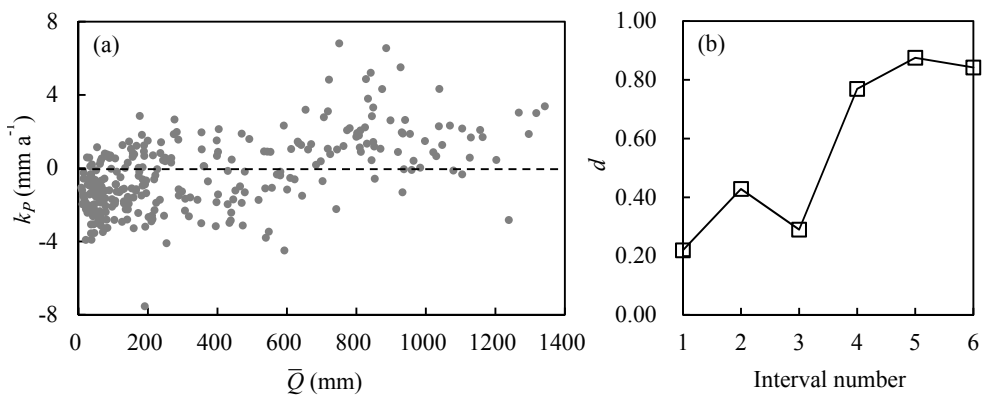

Figure 10. (a) Relationship between observed precipitation trends $k_{\mathrm{P}}$ and mean annual runoff $\bar{Q}$ for the study catchments during the period 1956-2000. (b) Values of $d$ in each interval according to $\bar{Q}$. Interval numbers 1 to 6 correspond to six intervals of 0-200, 200-400, 400-600, 600-800, 800-1000, and 1000-1400, respectively.

of $k_{P}$ on the runoff trends. Therefore, from the perspective of climate change, the more uneven precipitation resulted in more uneven runoff, thereby producing the DDWW pattern.

\subsection{Predicting future trends using the GCM projections}

Based on the GCM projections, Eq. (8b) predicts the future runoff trends $\Delta \bar{Q}_{\mathrm{e}}$ between the periods $1956-2000$ and 2001-2050. The results showed great discrepancies in $\Delta \bar{Q}_{\mathrm{e}}$ among the five GCMs even under the same scenario, whereas the model-averaged results under different scenarios were close (Fig. 11). The $C_{\mathrm{v}}$ values of $\Delta \bar{Q}_{\mathrm{e}}$ in each catchment are presented in Fig. 12. Taking the RCP2.6 scenario as an example, over two-fifths $(41.9 \%)$ of the catchments have a $C_{\mathrm{v}}$ value larger than 0.5 , which is indicative of considerable uncertainty in the various models reported by previous 
× GFDL-ESM2M + HadGEM2-ES - IPSL-CM5A-LR • MIROC-ESM-CHEM ○ NorESM1-M " Model-averaged
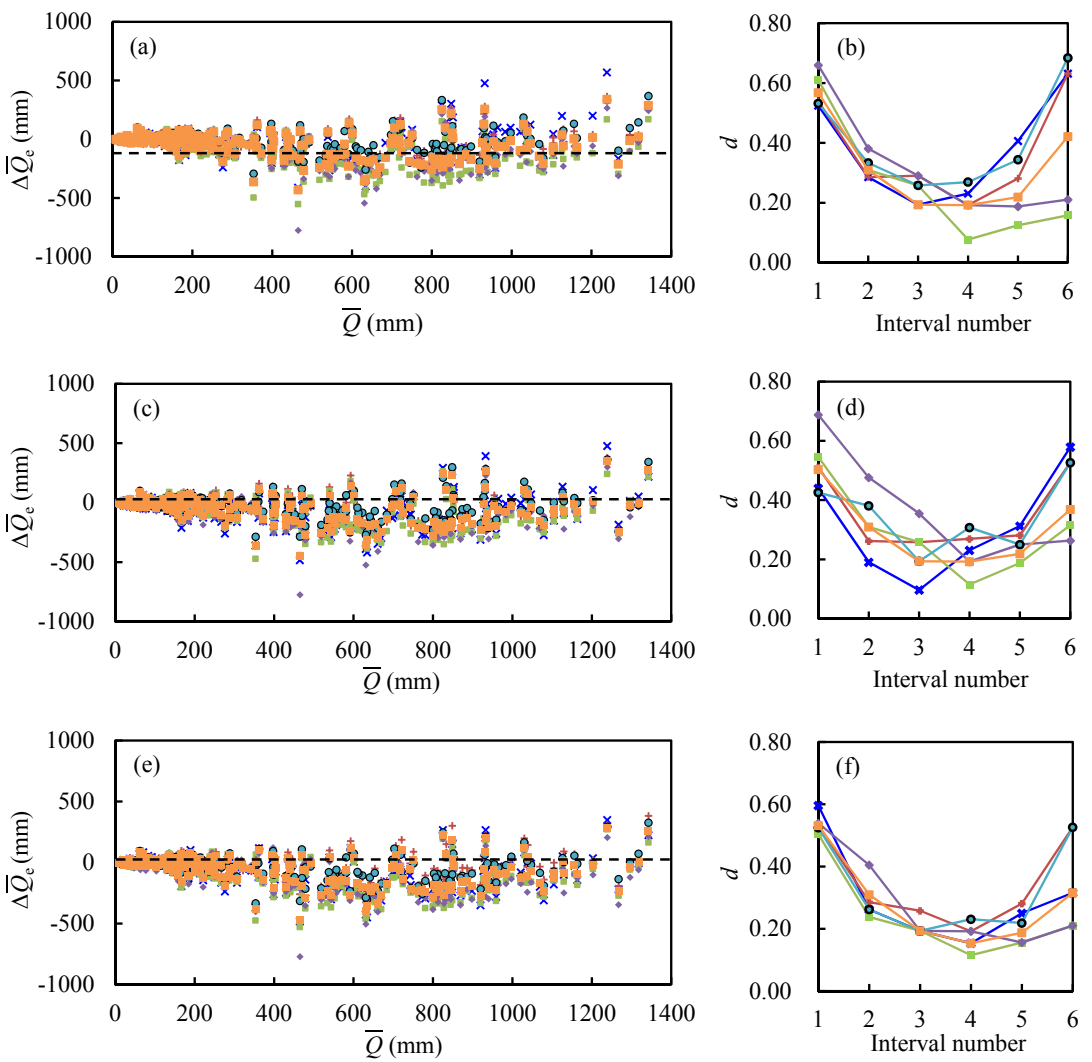

Figure 11. Projections of future trends $\Delta \bar{Q}_{\mathrm{e}}$ under RCP2.6 (top panels), RCP4.5 (middle panels), and RCP8.5 (bottom panels) scenarios for the period 2001-2050. (a, c, e) Relationship between projected $\Delta \bar{Q}_{\mathrm{e}}$ of the five models and their means and mean annual runoff $\bar{Q}$. (b, d, f) Values of $d$ in each interval according to $\bar{Q}$ based on $\Delta \bar{Q}_{\mathrm{e}}$ of the five models and their means. Interval numbers 1 to 6 correspond to six intervals of $0-200,200-400,400-600,600-800,800-1000$, and 1000-1400, respectively.
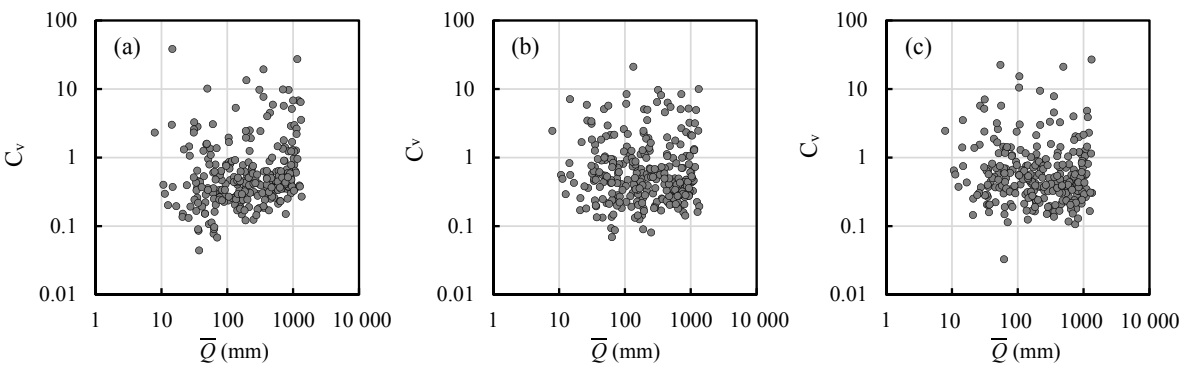

Figure 12. $C_{\mathrm{v}}$ values of projected future trends $\Delta \bar{Q}_{\mathrm{e}}$ under (a) RCP2.6, (b) RCP4.5, and (c) RCP8.5 scenarios.

studies (e.g. Greve et al., 2014; Kumar et al., 2016). However, the proposed DDWW pattern is no longer suitable under the three scenarios regardless of the model selected because $d$ decreased as $\bar{Q}$ increased except for interval 6, which showed an increase in contrast to the DDWW pattern. These results do not imply an obvious alleviation of the uneven water resource distribution. Conversely, they suggest that most areas of China (more than $60 \%$, as calculated from Table 3) will experience water resource shortages under the projected climate changes, whereas the conditions of the driest (interval 6) and wettest (interval 1) areas will be relatively slight. Furthermore, the main meteorological factor controlling the future trends was identified on the basis of the mean results of the five GCMs. Figure 13 shows that the trend in $P(\Delta \bar{P})$ is no longer the controlling factor because only $40 \%$ of the catchments had $\left|\frac{\varepsilon_{0} \Delta \overline{E_{\mathrm{p}}}}{\varepsilon_{P} \Delta \bar{P}}\right|$ values smaller than 1 .

The spatial distribution of model-averaged relative changes in $\bar{Q}\left(\Delta \bar{Q}_{\mathrm{e}} / \bar{Q}\right)$ is shown in Fig. 14. The results under 

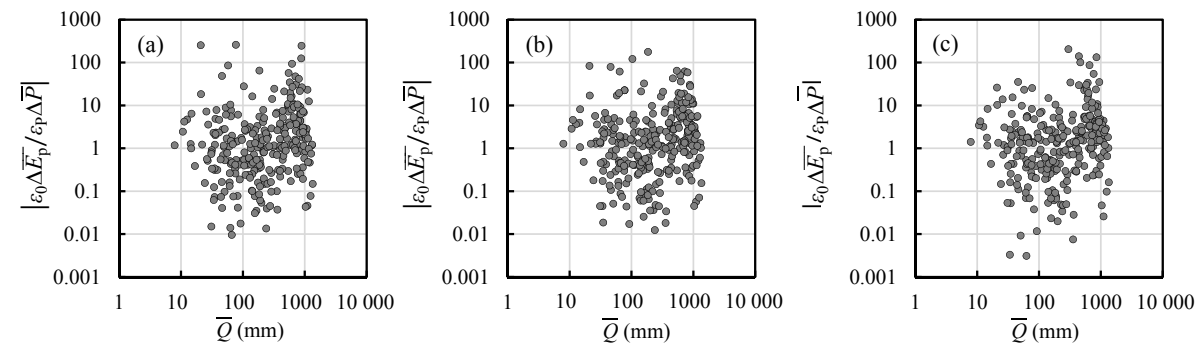

Figure 13. Analysis of the controlling factor in the projected climate change under (a) RCP2.6, (b) RCP4.5, and (c) RCP8.5 scenarios.
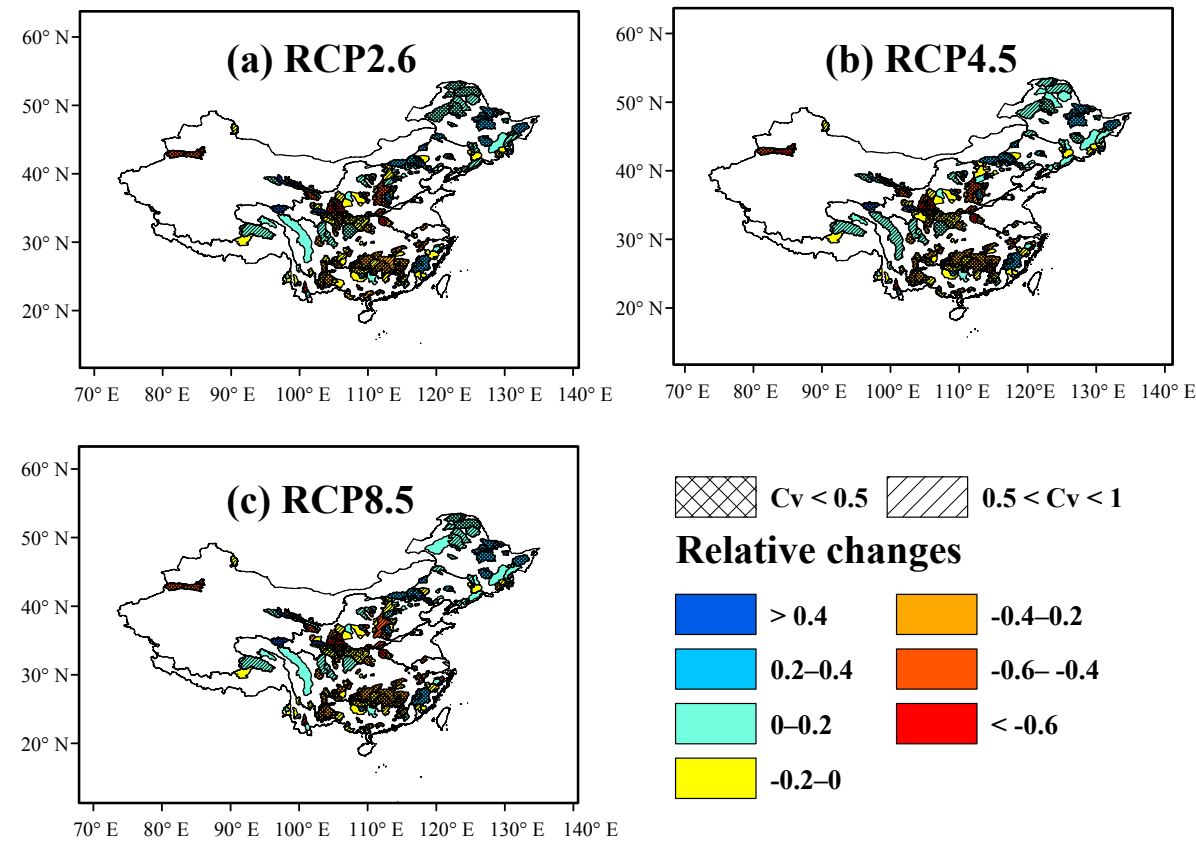

Figure 14. Spatial distribution of the model-averaged relative changes in mean annual runoff $\bar{Q}\left(=\Delta \bar{Q}_{\mathrm{e}} / \bar{Q}\right)$ for the period 2001-2050 under (a) RCP2.6, (b) RCP4.5, and (c) RCP8.5 scenarios.

the three scenarios were similar. Red regions indicate catchments in which $\bar{Q}$ will fall by more than $60 \%$ relative to the historical value; most of these regions are located in the Yellow River basin with relatively high certainty $\left(C_{\mathrm{v}}<0.5\right)$. The most severe situation occurred in a catchment situated in the Yangtze River basin, where the runoff is predicted to be nearly zero and the $C_{\mathrm{v}}$ was less than 0.2 . In contrast, dark blue areas indicate catchments in which $\bar{Q}$ is projected to increase by more than $40 \%$. These catchments are located primarily in the Inland River basin, except for northwest China, where catchments will suffer from a shortage of fresh water. Instead of continuing to become drier, catchments in northeast and north China are projected to generate more runoff in the future, whereas catchments in the lower reaches of the Yangtze River basin will experience considerable reductions in runoff despite historical increases. These are the most obvious distinctions between the projected and historical runoff changes. Thus, the DDWW pattern failed to accurately characterize these future patterns.

An inevitable concern about the GCM outputs is their uncertainty, which determines the reliability of the projected results. To examine the uncertainty, one workable method is to compare meteorological observations with simulations for the same period of 1956-2000. Taking the results of the GFDL-ESM2M model as an example (Fig. 15), $\bar{P}$ was effectively simulated except for some obvious incorrectly estimated points far from the $y=x$ line. However, simulations of $\bar{E}_{\mathrm{p}}$ show tremendous deviations, resulting in no obvious linear relationship between the simulated and observed values. This simple comparison directly highlights the unreliability of the GCM outputs. 
Table 3. Numbers of catchments with $\Delta \bar{Q}_{\mathrm{e}}>0$ and respective $d$ in each interval based on $\bar{Q}$ of five GCMs and their means in the analysis of the projected trends under three scenarios. Interval numbers based on $\bar{Q}$ and $\varphi$ are consistent with those in Table 1 , as are the interval range and the sample size of each interval. $d$ is the proportion of catchments becoming wetter in each interval.

\begin{tabular}{|c|c|c|c|c|c|c|c|}
\hline & $\begin{array}{l}\text { Interval } \\
\text { number }\end{array}$ & 1 & 2 & 3 & 4 & 5 & 6 \\
\hline \multicolumn{8}{|c|}{$\mathrm{RCP} 2.6$} \\
\hline \multirow{2}{*}{ GFDL-ESM2M } & Number & 74 & 12 & 6 & 6 & 13 & 12 \\
\hline & $d$ & 0.52 & 0.29 & 0.19 & 0.23 & 0.41 & 0.63 \\
\hline \multirow{2}{*}{ HadGEM2-ES } & Number & 76 & 12 & 9 & 5 & 9 & 12 \\
\hline & $d$ & 0.54 & 0.29 & 0.29 & 0.19 & 0.28 & 0.63 \\
\hline \multirow{2}{*}{ IPSL-CM5A-LR } & Number & 86 & 13 & 8 & 2 & 4 & 3 \\
\hline & $d$ & 0.61 & 0.31 & 0.26 & 0.08 & 0.13 & 0.16 \\
\hline \multirow{2}{*}{ MIROC-ESM-CHEM } & Number & 93 & 16 & 9 & 5 & 6 & 4 \\
\hline & $d$ & 0.66 & 0.38 & 0.29 & 0.19 & 0.19 & 0.21 \\
\hline \multirow{2}{*}{ NorESM1-M } & Number & 75 & 14 & 8 & 7 & 11 & 13 \\
\hline & $d$ & 0.53 & 0.33 & 0.26 & 0.27 & 0.34 & 0.68 \\
\hline \multirow{2}{*}{ Model-averaged } & Number & 80 & 13 & 6 & 5 & 7 & 8 \\
\hline & $d$ & 0.57 & 0.31 & 0.19 & 0.19 & 0.22 & 0.42 \\
\hline \multicolumn{8}{|c|}{$\mathrm{RCP} 4.5$} \\
\hline \multirow{2}{*}{ GFDL-ESM2M } & Number & 62 & 8 & 3 & 6 & 10 & 11 \\
\hline & $d$ & 0.44 & 0.19 & 0.10 & 0.23 & 0.31 & 0.58 \\
\hline \multirow{2}{*}{ HadGEM2-ES } & Number & 72 & 11 & 8 & 7 & 9 & 10 \\
\hline & $d$ & 0.51 & 0.26 & 0.26 & 0.27 & 0.28 & 0.53 \\
\hline \multirow{2}{*}{ IPSL-CM5A-LR } & Number & 77 & 13 & 8 & 3 & 6 & 6 \\
\hline & $d$ & 0.55 & 0.31 & 0.26 & 0.12 & 0.19 & 0.32 \\
\hline \multirow{2}{*}{ MIROC-ESM-CHEM } & Number & 97 & 20 & 11 & 5 & 8 & 5 \\
\hline & $d$ & 0.69 & 0.48 & 0.35 & 0.19 & 0.25 & 0.26 \\
\hline \multirow{2}{*}{ NorESM1-M } & Number & 60 & 16 & 6 & 8 & 8 & 10 \\
\hline & $d$ & 0.43 & 0.38 & 0.19 & 0.31 & 0.25 & 0.53 \\
\hline \multirow{2}{*}{ Model-averaged } & Number & 71 & 13 & 6 & 5 & 7 & 7 \\
\hline & $d$ & 0.50 & 0.31 & 0.19 & 0.19 & 0.22 & 0.37 \\
\hline \multicolumn{8}{|c|}{ RCP8.5 } \\
\hline \multirow{2}{*}{ GFDL-ESM2M } & Number & 84 & 11 & 6 & 4 & 8 & 6 \\
\hline & $d$ & 0.60 & 0.26 & 0.19 & 0.15 & 0.25 & 0.32 \\
\hline \multirow{2}{*}{ HadGEM2-ES } & Number & 75 & 12 & 8 & 5 & 9 & 10 \\
\hline & $d$ & 0.53 & 0.29 & 0.26 & 0.19 & 0.28 & 0.53 \\
\hline \multirow{2}{*}{ IPSL-CM5A-LR } & Number & 71 & 10 & 6 & 3 & 5 & 4 \\
\hline & $d$ & 0.50 & 0.24 & 0.19 & 0.12 & 0.16 & 0.21 \\
\hline \multirow{2}{*}{ MIROC-ESM-CHEM } & Number & 76 & 17 & 6 & 5 & 5 & 4 \\
\hline & $d$ & 0.54 & 0.40 & 0.19 & 0.19 & 0.16 & 0.21 \\
\hline \multirow{2}{*}{ NorESM1-M } & Number & 74 & 11 & 6 & 6 & 7 & 10 \\
\hline & $d$ & 0.52 & 0.26 & 0.19 & 0.23 & 0.22 & 0.53 \\
\hline \multirow{2}{*}{ Model-averaged } & Number & 75 & 13 & 6 & 4 & 6 & 6 \\
\hline & $d$ & 0.53 & 0.31 & 0.19 & 0.15 & 0.19 & 0.32 \\
\hline
\end{tabular}

\section{Discussion}

In the present work, a new method which is not limited to the artificial selection of the threshold to partition dry and wet regions was proposed to examine the DDWW pattern. Our results confirm that a feasible DDWW pattern exists in the historical runoff trends across China. However, if we adopt the same threshold $\varphi=2$ as in the study of Greve et al. (2014) to check Fig. 5, the opposite result would be obtained such that the DDWW pattern would not hold. Therefore, adopting the new method may also verify the validity of the DDWW pattern in previous studies. Roderick et al. (2014) plotted the relationship between GCM-based gridded $\Delta(P-E)$ and $P-E$ over land (Fig. 1f in Roderick et al., 2014) to argue that the proportional relationship between them revealed by Held and Soden (2006) does not hold over land. Neverthe- 

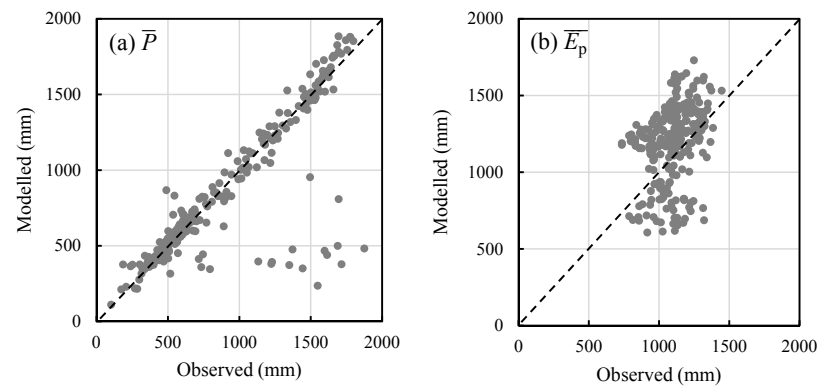

Figure 15. Comparison of the observed meteorological data with the simulations from the GFDL-ESM2M model for the period 1956-2000. (a) Mean annual precipitation $\bar{P}$ and (b) mean annual potential evapotranspiration $\overline{E_{\mathrm{p}}}$.

less, from the perspective of the new method, the relationship appears to be consistent with the DDWW pattern including the possibility of $\Delta(P-E)>0$ becoming larger as $P-E$ increases. Additionally, the DDWW pattern might also hold in the study of Greve et al. (2014) according to Fig. 4c in that study and the distribution of $\varphi$ across the world. Therefore, a follow-up study will adapt the proposed method to the worldwide scale to examine the DDWW pattern globally.

Based on a Budyko-based framework, our findings suggest that climate change is the main factor of the historical runoff trends in China and that $k_{P}$ is the most significant factor associated with climate change. Roderick et al. (2014) reported a similar result in their research of GCM outputs (CMIP3) such that the changes in water availability $(\Delta(P-E))$ are dominated by the changes in $P(\Delta P)$ globally. Despite high correlation between $k_{Q}$ and $k_{Q_{\mathrm{e}}}$, the Budyko-based framework underestimated the observed changes in runoff. This is because the framework quantifies only the effects of climate change. The estimated deviations may stem from the neglect of other influencing factors such as ecological and environmental changes, which result in changes in the catchment properties ( $d n$ in Eq. 6) which were assumed in this study to be constant.

In this study, $E_{\mathrm{p}}$ was calculated by using the Penman equation, which is considered to be the most effective method (Zhang et al., 2001) and is strongly recommended by Shuttleworth (2012). This method for estimating $E_{\mathrm{p}}$ was also adopted by other studies such as Yang et al. (2014) and Xu et al. (2015). However, Roderick et al. (2015) suggested using net radiation instead of $E_{\mathrm{p}}$ in the Budyko hypothesis. Kumar et al. (2016) compared runoff change projections obtained by these two different methods and found similar results. Therefore, it is likely that the use of $E_{\mathrm{p}}$ or net radiation had little influence in our results.

Great discrepancy was noted between the GCM-simulated and observed $\bar{E}_{\mathrm{p}}$, whereas GCM-simulated and observed $\bar{P}$ showed significant agreement (Fig. 15). This substantial distinction in GCM performance in the $\bar{P}$ and $\bar{E}_{\mathrm{p}}$ simulations might evoke doubt about the reliability of the bias-corrected
GCM outputs used in this study. Actually, the bias-correction process was implemented for all GCM outputs, which means that all variables required for calculating $E_{\mathrm{p}}$ were corrected simultaneously. We speculate that this factor might relate to the disparate effectiveness of the bias-correction process in the different outputs, resulting in a good fit to $P$ and a bad fit to $E_{\mathrm{p}}$.

\section{Conclusions}

Based on the analysis of restored discharge in 291 catchments across China from 1956 to 2000, this study proposed a suitable DDWW pattern of drier regions being more likely to become drier, and wetter regions being more likely to become wetter, which implies that the distribution of water resources in China has become increasingly uneven since the 1950s. This pattern holds in studies adopting both $\bar{Q}$ and $\varphi$ as the indicators of water availability. Furthermore, a framework based on the Budyko hypothesis revealed that the runoff changes can be attributed mainly to climate change and that $k_{P}$ is the controlling factor. According to the projections of five GCMs from CMIP5 during the period 20012050 , the proposed DDWW pattern is no longer suitable. The model-averaged results suggest that more than $60 \%$ of catchments will experience water resource shortages under future climate change. In addition, only $40 \%$ of the study catchments will be primarily controlled by $\Delta \bar{P}$, which is different from the phenomenon where the runoff change is controlled by precipitation in about $90 \%$ catchments in the historical period. The catchments in northeast and north China, which have become drier, will generate more runoff in the future; those in the lower reaches of the Yangtze River basin, which have become wetter, will experience considerable reductions in runoff. These changes represent the most obvious differences between the projected and historical runoff changes. Nevertheless, the projected conclusions remain tentative owing to the enormous unreliability of the GCM outputs as indicated by the extremely low correlations between the simulated and observed $\bar{E}_{\mathrm{p}}$ values for the period 1956-2000.

The results of this study may be helpful in exploring the rule of spatial heterogeneity in runoff trends and for supplementing the study of the DDWW pattern under climate change. Although some studies have suspected the existence of the DDWW pattern on land, this study confirms that the DDWW pattern has actually existed across China in history. Realizing the more uneven distribution of water resources across China is essential for the Chinese government to better cope with climate change and to rationally manage and utilize water resources. Moreover, the proposed method, which divides catchments into several intervals representing different aridity degrees instead of assigning a threshold to partition wet and dry regions, can be easily adapted to the global study of the DDWW pattern for drawing more generalized conclusions worldwide. 
Data availability. Three data sets were used for this study. The annual restored discharge data set is available online in the Supplement. The observed meteorological data set is available for research purposes at the China Meteorological Data Service Center (CMDC) (http://data.cma.cn/data/cdcdetail/dataCode/ SURF_CLI_CHN_MUL_DAY_V3.0.html). The CMIP5-projected data set is distributed by the ISI-MIP on its own website (http: //www.isi-mip.org). 


\section{Appendix A: Estimate of $E_{\mathrm{p}}$ by the Penman equation}

The procedure for using the Penman equation to estimate $E_{\mathrm{p}}$ $\left(\mathrm{mm} \mathrm{day}^{-1}\right)$ based on the GCM outputs is described in detail in this appendix. The Penman equation can be written as (Yang and Yang, 2011)

$E_{\mathrm{p}}=\frac{0.408 \Delta\left(R_{\mathrm{n}}-G\right)+2.624 \gamma\left(1+0.536 u_{2}\right)(1-\mathrm{RH}) e_{\mathrm{s}}}{\Delta+\gamma}$,

where $e_{\mathrm{S}}$ is the saturated vapour pressure $(\mathrm{kPa}), \Delta$ is the slope of the saturated vapour pressure versus the air temperature curve $\left(\mathrm{kPa}^{\circ} \mathrm{C}^{-1}\right)$ when the saturated vapour pressure equals $e_{\mathrm{s}}, R_{\mathrm{n}}$ is the net radiation $\left(\mathrm{MJ} \mathrm{m}^{-2}\right.$ day $\left.^{-1}\right), G$ is the soil heat flux $\left(\mathrm{MJ} \mathrm{m}^{-2} \mathrm{day}^{-1}\right), \gamma$ is a psychometric constant

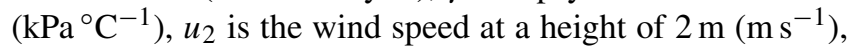
and $\mathrm{RH}$ is the relative humidity (\%) (Yang and Yang, 2011).

The form of the saturated vapour pressure versus the air temperature curve is

$e(T)=0.6108 \exp \left(\frac{17.27 T}{T+237.3}\right)$,

where $T$ denotes the daily air temperature, and $e_{\mathrm{S}}$ of the day can be calculated by

$e_{\mathrm{s}}=\frac{e\left(T_{\max }\right)+e\left(T_{\min }\right)}{2}$,

where $T_{\max }$ and $T_{\min }$ are maximum and minimum daily air temperatures, respectively.

The GCM outputs are daily $T_{\max }, T_{\min }$ (which can be used to calculate $e_{\mathrm{s}}$ and $\Delta$ ), $u_{2}$, and RH. Assuming $G$ equals 0 , and if we compute $R_{\mathrm{n}}$, we can use Eq. (A1) to estimate $E_{\mathrm{p}}$. The process of utilizing the solar radiation $\left(R_{\mathrm{S}}\right)$ to compute $R_{\mathrm{n}}$ is described below.

Firstly, we calculate the incoming net short-wave radiation $\left(R_{\mathrm{ns}}\right)$ by

$R_{\mathrm{ns}}=(1-\alpha) R_{\mathrm{s}}$,

where $\alpha$ denotes the albedo.

Next, the net outgoing long-wave radiation $\left(R_{\mathrm{nl}}\right)$ is estimated by

$$
\begin{aligned}
R_{\mathrm{nl}}= & \sigma\left(\frac{T_{\max }^{4}+T_{\min }^{4}}{2}\right)\left(0.34-0.14 \sqrt{e_{\mathrm{a}}}\right) \\
& \left(1.35 \frac{R_{\mathrm{s}}}{R_{\mathrm{s}_{0}}}-0.35\right),
\end{aligned}
$$

where $\sigma$ is the Stefan-Boltzmann constant $\left(=4.903 \times 10^{-9} \mathrm{MJ} \mathrm{K}^{-4} \mathrm{~m}^{-2} \mathrm{day}^{-1}\right), \quad e_{\mathrm{a}}$ is the actual vapour pressure $\left(=e_{\mathrm{S}} \times \mathrm{RH}\right)$, and $R_{\mathrm{S}_{0}}$ is the clear-sky solar radiation, which can be computed by

$$
R_{\mathrm{S}_{0}}=\left(0.75+2 \times 10^{-5} z\right) R_{\mathrm{a}},
$$

where $z$ is the station elevation above sea level $(\mathrm{m})$, which is available from the GCMs, and $R_{\mathrm{a}}$ is the extraterrestrial radiation $\left(\mathrm{MJ} \mathrm{m}^{-2} \mathrm{day}^{-1}\right.$ ) determined by Eqs. (21) to (25) in Allen et al. (1998).

Finally, by subtracting $R_{\mathrm{nl}}$ from $R_{\mathrm{ns}}$, we obtain $R_{\mathrm{n}}$.

\section{Appendix B: Derivation of framework for estimating $k_{Q}$ and $\Delta \bar{Q}$}

This appendix provides an explicit description of the derivation of the framework for estimating $k_{Q}$ and $\Delta \bar{Q}$ from Eq. (8). Substituting Eq. (8) into Eq. (2) yields

$k_{Q}=\frac{\sum_{i=1}^{m}\left(t_{i}-\bar{t}\right)\left(\varepsilon_{P} \Delta P_{i}+\varepsilon_{0} \Delta E_{\mathrm{p}_{i}}\right)}{\sum_{i=1}^{m}\left(t_{i}-\bar{t}\right)^{2}}$.

This equation can be transformed into

$k_{Q}=\varepsilon_{P} \frac{\sum_{i=}^{m}\left(t_{i}-\bar{t}\right) \Delta P_{i}}{\sum_{i=1}^{m}\left(t_{i}-\bar{t}\right)^{2}}+\varepsilon_{0} \frac{\sum_{i=1}^{m}\left(t_{i}-\bar{t}\right) \Delta E_{\mathrm{p}_{i}}}{\sum_{i=1}^{m}\left(t_{i}-\bar{t}\right)^{2}}$.

Recalling the definition of the trend in this study, Eq. (B2) can be considered as a linear combination of $k_{P}$ and $k_{E_{\mathrm{p}}}$ :

$k_{Q}=\varepsilon_{P} k_{P}+\varepsilon_{0} k_{E_{\mathrm{p}}}$.

Equation (3) can be rewritten as

$\Delta \bar{Q}=\frac{\sum_{i=1}^{m} Q_{\mathrm{p}_{i}}-m \bar{Q}}{m}$.

Recombination of the variables leads to the following expression:

$\Delta \bar{Q}=\frac{\sum_{i=1}^{m}\left(Q_{\mathrm{p}_{i}}-\bar{Q}\right)}{m}$.

Similarly, the substitution of Eq. (8) yields

$\Delta \bar{Q}=\frac{\sum_{i=1}^{m}\left(\varepsilon_{P} \Delta P_{i}+\varepsilon_{0} \Delta E_{\mathrm{p}_{i}}\right)}{m}$.

We finally obtain the target equation:

$\Delta \bar{Q}=\varepsilon_{P} \Delta \bar{P}+\varepsilon_{0} \Delta \bar{E}_{\mathrm{p}}$. 


\section{The Supplement related to this article is available online at doi:10.5194/hess-21-2233-2017-supplement.}

Competing interests. The authors declare that they have no conflict of interest.

Acknowledgements. This research was partly supported by funding from the National Natural Science Foundation of China (grant nos. 51622903 and 51379098), the National Program for Support of Top-Notch Young Professionals, and the Program from the State Key Laboratory of Hydro-Science and Engineering of China (grant nos. sklhse-2016-A-02 and 2017-KY-01). The authors are grateful to the editor, Jan Seibert, as well as Michael Roderick and the other anonymous referee for providing helpful comments.

Edited by: J. Seibert

Reviewed by: M. Roderick and one anonymous referee

\section{References}

Alkama, R., Marchand, L., Ribes, A., and Decharme, B.: Detection of global runoff changes: results from observations and CMIP5 experiments, Hydrol. Earth Syst. Sci., 17, 2967-2979, doi:10.5194/hess-17-2967-2013, 2013.

Allan, R. P., Soden, B. J., John, V. O., Ingram, W., and Good, P.: Current changes in tropical precipitation, Environ. Res. Lett., 5, 025205, doi:10.1088/1748-9326/5/2/025205, 2010.

Allen, R. G., Pereira, L. S., Raes, D., and Smith, M.: Crop evapotranspiration - Guidelines for computing crop water requirements, FAO Irrigation and drainage paper 56, FAO, Rome, 1998.

Arnell, N. W.: Climate change and global water resources, Global Environ. Change, 9, S31-S49, 1999.

Budyko, M. I.: Evaporation under Natural Conditions, Israel Program for Scientific Translations, Jerusalem, 1948.

Chou, C. and Neelin, J. D.: Mechanisms of global warming impacts on regional tropical precipitation, J. Climate, 17, 2688-2701, doi:10.1175/1520-0442(2004)017<2688:MOGWIO>2.0.CO;2, 2004.

Chou, C., Neelin, J. D., Chen, C., and Tu, J.: Evaluating the "Rich-Get-Richer" Mechanism in Tropical Precipitation Change under Global Warming, J. Climate, 22, 1982-2005, doi:10.1175/2008JCLI2471.1, 2009.

Chou, C., Chiang, J. C. H., Lan, C., Chung, C., Liao, Y., and Lee, C.: Increase in the range between wet and dry season precipitation, Nat. Geosci., 6, 263-267, doi:10.1038/ngeo1744, 2013.

Choudhury, B. J.: Evaluation of an empirical equation for annual evaporation using field observations and results from a biophysical model, J. Hydrol., 216, 99-110, doi:10.1016/S00221694(98)00293-5, 1999.

Dai, A., Qian, T., Trenberth, K. E., and Milliman, J. D.: Changes in continental freshwater discharge from 1948 to 2004, J. Climate, 22, 2773-2792, doi:10.1175/2008JCLI2592.1, 2009.

Durack, P. J., Wijffels, S. E., and Matear, R. J.: Ocean Salinities Reveal Strong Global Water Cycle Intensification During 1950 to 2000 , Science, 336, 455-458, doi:10.1126/science.1212222, 2012.
Fu, B.: On the calculation of the evaporation from land surface, Scienta Atmos. Sin., 5, 23-31, 1981.

Greve, P., Orlowsky, B., Mueller, B., Sheffield, J., Reichstein, M., and Seneviratne, S. I.: Global assessment of trends in wetting and drying over land, Nat. Geosci., 7, 716-721, doi:10.1038/ngeo2247, 2014.

Guo, W., Liu, S., Yao, X., Xu, J., Shangguan, D., Wu, L., Zhao, J., Liu, Q., Jiang, Z., Wei, J., Bao, W., Yu, P., Ding, L., Li, G., Li, P., Ge, C., and Wang, Y.: The second glacier inventory dataset of China (Version 1.0), Cold and Arid Regions Science Data Center, Lanzhou, doi:10.3972/glacier.001.2013.db, 2014.

Hagemann, S., Chen, C., Haerter, J. O., Heinke, J., Gerten, D., and Piani, C.: Impact of a statistical bias correction on the projected hydrological changes obtained from three GCMs and two hydrology models, J. Hydrometeorol., 12, 556-578, 2011.

Hamlet, A. F., Mote, P. W., Clark, M. P., and Lettenmaier, D. P.: Twentieth-century trends in runoff, evapotranspiration, and soil moisture in the Western United States, J. Climate, 20, 14681486, doi:10.1175/JCLI4051.1, 2007.

Held, I. M. and Soden, B. J.: Robust responses of the hydrological cycle to global warming, J. Climate, 19, 5686-5699, doi:10.1175/JCLI3990.1, 2006.

Koster, R. D. and Suarez, M. J.: A simple framework for examining the interannual variability of land surface moisture fluxes, J. Climate, 12, 1911-1917, doi:10.1175/1520 0442(1999)012<1911:ASFFET>2.0.CO;2, 1999.

Kumar, S., Zwiers, F., Dirmeyer, P. A., Lawrence, D. M., Shrestha, R., and Werner, A. T.: Terrestrial contribution to the heterogeneity in hydrological changes under global warming, Water Resour. Res., 52, 3127-3142, doi:10.1002/2016WR018607, 2016.

Legates, D. R. and McCabe, G. J.: Evaluating the use of "goodness-of-fit" measures in hydrologic and hydroclimatic model validation, Water Resour. Res., 35, 233-241, doi:10.1029/1998WR900018, 1999.

Lim, W. H. and Roderick, M. L.: An atlas of the global water cycle: based on the IPCC AR4 Models, Australian National University Press, Canberra, 2009.

Liu, C., and Allan, R. P.: Observed and simulated precipitation responses in wet and dry regions $1850-2100$, Environ. Res. Lett., 8, 034002, doi:10.1088/1748-9326/8/3/034002, 2013.

Milly, P. C. D., Dunne, K. A., and Vecchia, A. V.: Global pattern of trends in streamflow and water availability in a changing climate, Nature, 438, 347-350, doi:10.1038/nature04312, 2005.

Oudin, L., Andréassian, V., Lerat, J., and Michel, C.: Has land cover a significant impact on mean annual streamflow? An international assessment using 1508 catchments, J. Hydrol., 357, 303316, doi:10.1016/j.jhydrol.2008.05.021, 2008.

Pasquini, A. I. and Depetris, P. J.: Discharge trends and flow dynamics of South American rivers draining the southern Atlantic seaboard: an overview, J. Hydrol., 333, 385-399, doi:10.1016/j.jhydrol.2006.09.005, 2007.

Penman, H. L.: Natural evaporation from open water, bare soil and grass, P. Roy. Soc. A, 193, 120-145, doi:10.1098/rspa.1948.0037, 1948.

Piani, C., Weedon, G. P., Best, M., Gomes, S. M., Viterbo, P., Hagemann, S., and Haerter, J. O.: Statistical bias correction of global simulated daily precipitation and temperature for the application of hydrological models, J. Hydrol., 395, 199-215, 2010. 
Piao, S., Ciais, P., Huang, Y., Shen, Z., Peng, S., Li, J., Zhou, L., Liu, H., Ma, Y., Ding, Y., Friedlingstein, P., Liu, C., Tan, K., Yu, Y., Zhang, T., and Fang, J.: The impacts of climate change on water resources and agriculture in China, Nature, 467, 43-51, doi:10.1038/nature09364, 2010.

Pike, J. G.: The estimation of annual run-off from meteorological data in a tropical climate, J. Hydrol., 2, 116-123, 1964.

Roderick, M. L. and Farquhar, G. D.: A simple framework for relating variations in runoff to variations in climatic conditions and catchment properties, Water Resour. Res., 47, W00G07, doi:10.1029/2010WR009826, 2011.

Roderick, M. L., Sun, F., Lim, W. H., and Farquhar, G. D.: A general framework for understanding the response of the water cycle to global warming over land and ocean, Hydrol. Earth Syst. Sci., 18, 1575-1589, doi:10.5194/hess-18-1575-2014, 2014.

Roderick, M. L., Greve, P., and Farquhar, G. D.: On the assessment of aridity with changes in atmospheric $\mathrm{CO}_{2}$, Water Resour. Res., 51, 5450-5463, doi:10.1002/2015WR017031, 2015.

Shuttleworth, W. J.: Daily estimates of evaporation, in: Terrestrial Hydrometeorology, John Wiley, Chichester, UK, 334-358, doi:10.1002/9781119951933, 2012.

Stahl, K., Hisdal, H., Hannaford, J., Tallaksen, L. M., van Lanen, H. A. J., Sauquet, E., Demuth, S., Fendekova, M., and Jódar, J.: Streamflow trends in Europe: evidence from a dataset of nearnatural catchments, Hydrol. Earth Syst. Sci., 14, 2367-2382, doi:10.5194/hess-14-2367-2010, 2010.

Teng, J., Chiew, F. H. S., Vaze, J., Marvanek, S., and Kirono, D. G. C.: Estimation of climate change impact on mean annual runoff across continental Australia using Budyko and Fu equations and hydrological models, J. Hydrometeorol., 13, 10941106, doi:10.1175/JHM-D-11-097.1, 2012.

Wang, D. and Tang, Y.: A one-parameter Budyko model for water balance captures emergent behavior in Darwinian hydrologic models, Geophys. Res. Lett., 41, 4569-4577, 2014.

Xiong, L. and Guo, S.: Appraisal of Budyko formula in calculating long-term water balance in humid watersheds of southern China, Hydrol. Process., 26, 1370-1378, doi:10.1002/hyp.8273, 2012.
Xu, K., Yang, D., Yang, H., Li, Z., Qin, Y., and Shen, Y.: Spatio-temporal variation of drought in China during 19612012: A climatic perspective, J. Hydrol., 526, 253-264, doi:10.1016/j.jhydrol.2014.09.047, 2015.

$\mathrm{Xu}, \mathrm{X}$., Yang, D., Yang, H., and Lei, H.: Attribution analysis based on the Budyko hypothesis for detecting the dominant cause of runoff decline in Haihe basin, J. Hydrol., 510, 530-540, doi:10.1016/j.jhydrol.2013.12.052, 2014.

Yang, D., Sun, F., Liu, Z., Cong, Z., Ni, G., and Lei, Z.: Analyzing spatial and temporal variability of annual water-energy balance in nonhumid regions of China using the Budyko hypothesis, Water Resour. Res., 43, W04426, doi:10.1029/2006WR005224, 2007.

Yang, H. and Yang, D.: Derivation of climate elasticity of runoff to assess the effects of climate change on annual runoff, Water Resour. Res., 47, W07526, doi:10.1029/2010WR009287, 2011.

Yang, H., Yang, D., Lei, Z., and Sun, F.: New analytical derivation of the mean annual water-energy balance equation, Water Resour. Res., 44, W03410, doi:10.1029/2007WR006135, 2008.

Yang, H., Qi, J., Xu, X., Yang, D., and Lv, H.: The regional variation in climate elasticity and climate contribution to runoff across China, J. Hydrol., 517, 607-616, doi:10.1016/j.jhydrol.2014.05.062,2014.

Zhang, L., Dawes, W. R., and Walker, G. R.: Response of mean annual evapotranspiration to vegetation changes at catchment scale, Water Resour. Res., 37, 701-708, doi:10.1029/2000WR900325, 2001.

Zhang, L., Potter, N., Hickel, K., Zhang, Y., and Shao, Q.: Water balance modeling over variable time scales based on the Budyko framework - model development and testing, J. Hydrol., 360, 117-131, doi:10.1016/j.jhydrol.2008.07.021, 2008.

Zhou, S., Yu, B., Huang, Y., and Wang, G.: The complementary relationship and generation of the Budyko functions, Geophys. Res. Lett., 42, 1781-1790, 2015. 